\title{
Vitamin D Double-edged Sword Against COVID-19
}

\author{
Fahima Danesh Pouya ${ }^{1,{ }^{*}}$, Yousef Rasmi ${ }^{1,2}$, Mohadeseh Nemati ${ }^{1}$ and Elmira Roshani Asl ${ }^{1}$ \\ ${ }^{1}$ Department of Biochemistry, School of Medicine, Urmia University of Medical Sciences, Urmia, Iran \\ ${ }^{2}$ Cellular and Molecular Research Center, Urmia University of Medical Sciences, Urmia, Iran \\ "Corresponding author: Department of Biochemistry, School of Medicine, Urmia University of Medical Sciences, Urmia, Iran. Email: daneshpouya.f@umsu.ac.ir
}

Received 2020 November 21; Accepted 2021 January 31.

Keywords: SARS-CoV-2, Bradykinin, Vitamin D

\section{Dear editor,}

In late 2019, a viral disease called acute respiratory syndrome coronavirus 2 (SARS-CoV-2 or COVID-19) spread from China and has now infected many people worldwide (1). Generally, the immune system response to the infection is associated with inflammation, pain, and decreased tissue function (2). Patients with COVID-19 die in critical condition due to acute respiratory distress syndrome(ARDS) and dysfunction of several major organs. Increased release of cytokines plays a key role in the pathology of this disease (3). At present, the rapid spread of this disease due to the lack of effective control has caused serious concerns in patients with underlying conditions such as diabetes, cardiovascular diseases, autoimmunity, hypertension, and pulmonary diseases (4). No specific treatment has yet been found for COVID-19, and current drugs have not shown any desired function (5).

The SARS-CoV2 virus employs the angiotensinconverting enzyme 2 (ACE2) to enter host cells (6). The host protein of ACE2 is expressed in almost all tissues, but its expression is higher in the respiratory tissue epithelium, kidney, cardiovascular system, gastrointestinal tract, and type I and II alveolar cells $(7,8)$. The protein acts as one of the key components of the renin-angiotensin system (RAS). At the beginning of the RAS pathway, the renin enzyme, which is synthesized in the kidney, converts angiotensinogen (synthesized in the liver) to angiotensin I (AngI), which has 1 - 10 amino acids and subsequently is converted to Ang II ( 1 - 8 amino acids) by ACE. Through a pathway mediated by Ang II receptor type 1 (AT1R), Ang II triggers inflammation, fibrosis, hypertension, and oxidative stress. Angiotensin I and II peptides are converted to Ang $(1-7)$ by the act of endopeptidase (NEP) and ACE2 enzymes, respectively. The bioactive Ang- (1-7) peptide, through the Mas-receptor, initiates anti-inflammatory and anti-fibrotic processes and lowers blood pressure by inducing the release of nitric oxide (9).
When SARS-CoV-2 binds to ACE2, it prevents the conversion of Ang II to Ang-(1-7), resulting in the accumulation of Ang II and activation of inflammatory pathways (10). The virus also enhances the bradykinin (BDK) signaling pathway, exaggerating inflammation. This is because ACE2 inhibits the conversion of BDK to its bioactive derivative, des-Arg9 bradykinin (DABK), and prevents the formation of a complex between DABK and bradykinin B1 receptor (BDKB1R) in pulmonary epithelial cells, suppressing acute pulmonary inflammation. In a study to investigate ARDS, by knocking out the ACE2 gene in mice, it was reported that the lung disease incurred more severe clinical symptoms and greater vascular permeability along with pulmonary edema (11). The inhibition of pulmonary ACE2 by endotoxin inhalation caused severe lung damage in a mouse model due to the activation of the DABK/BDKB1R inflammatory pathway, increased proinflammatory factors such as C-X-C motif chemokine 5 (CXCL5), macrophage inflammatory protein 2 (MIP2), C$\mathrm{X}-\mathrm{C}$ motif chemokine 1 (KC), tumor necrosis factor-alpha (TNF- $\alpha$ ), and finally enhanced neutrophil infiltration into the lung (12). In lipopolysaccharide (LPS)-induced ARDS, inducing ACE2 expression increased the conversion of Ang II to Ang I, activated Ang-(1-7)/Mas-receptor-mediated antiinflammatory pathways, and suppressed nuclear factor$\kappa \mathrm{B}(\mathrm{NF}-\kappa \mathrm{B})$-mediated inflammatory reactions (13) and proinflammatory genes' expression (14).

Vitamin D belongs to the group of fat-soluble vitamins and has several roles in the body, acting as an important hormone and intestinal absorber of calcium, magnesium, and phosphate. It is derived from subcutaneous 7-dehydrocholesterol with the help of the sun's ultraviolet rays. The produced cholecalciferol (vitamin $\mathrm{D}_{3}$ ) is then converted to calcidiol (25-hydroxy $\mathrm{D}_{3}$ ) by the 25 -alphahydroxylase liver enzyme, which is the most important metabolite of vitamin $\mathrm{D}$ in the body and is used to determine vitamin D levels in serum. The active form of the vi- 
tamin, called calcitriol (1,25-dihydroxy $\left.\mathrm{D}_{3}\right)$, is produced by the 1-alpha hydroxylase renal enzyme (15).

Studies have shown that vitamin D plays a protective role against COVID-19 by reinforcing the immune system via reducing the production of TNF- $\alpha$ and interferon $\gamma($ IFN- $\gamma$ ), supporting cellular connections, and inducing regulatory T cells (16), finally culminating in reduced production of anti-inflammatory cytokines during acute lung injury (ALI) and ARDS (17). Moreover, vitamin D receptor (VDR) is highly expressed in the lungs. In mice models of LPS-induced ALI, more severe symptoms were observed in animals with knockout VDR gene; however, the use of paricalcitol (a vitamin D analog) prevented further damage to the alveolar tissue of these animals (18), partly via inducing ACE2 production and the anti-inflammatory Ang-(1-7)/Mas pathway and suppressing the renin and ACE/Ang II/AT1R inflammatory branch (19). In mice with LPS-induced ALI, vitamin D consumption increased the gene expression of ACE2 and VDR, which played significant roles in the recovering of mice (20). Nevertheless, increasing vitamin D levels up to the normal range can increase ACE2 expression, which like a double-edged sword, can cut RAS (Ang II/AT1R) and BDK (DABK/BDKB1R) inflammatory pathways (Figure 1), leading to severe pulmonary inflammation in COVID-19 patients.

\section{Footnotes}

Authors' Contribution: Concept and design: Fahima Danesh Pouya and Yousef Rasmi; Analysis and interpretation of data: Fahima Danesh Pouya and Yousef Rasmi; Drafting the manuscript: Fahima Danesh Pouya; Critical revision of the manuscript for important intellectual content: Fahima Danesh Pouya, Yousef Rasmi, Mohadeseh Nemati, and Elmira Roshani.

Conflict of Interests: The authors declare that there is no conflict of interest.

\section{References}

1. Zhu N, Zhang D, Wang W, Li X, Yang B, Song J, et al. A novel coronavirus from patients with pneumonia in China, 2019. $N$ Engl J Med. 2020;382(8):727-33. doi: 10.1056/NEJMoa2001017. [PubMed: 31978945]. [PubMed Central: PMC7092803].

2. Takeuchi O, Akira S. Pattern recognition receptors and inflammation.Cell.2010;140(6):805-20.doi:10.1016/j.cell.2010.01.022.[PubMed: 20303872].

3. Liu B, Li M, Zhou Z, Guan X, Xiang Y. Can we use interleukin6 (IL-6) blockade for coronavirus disease 2019 (COVID-19)-induced cytokine release syndrome (CRS)? J Autoimmun. 2020;111:102452. doi: 10.1016/j.jaut.2020.102452. [PubMed: 32291137]. [PubMed Central: PMC7151347].

4. Huang C, Wang Y, Li X, Ren L, Zhao J, Hu Y, et al. Clinical features of patients infected with 2019 novel coronavirus in Wuhan, China. Lancet. 2020;395(10223):497-506. doi: 10.1016/S0140-6736(20)30183-5. [PubMed: 31986264]. [PubMed Central: PMC7159299].
5. Malek Mahdavi A. A brief review of interplay between vitamin $\mathrm{D}$ and angiotensin-converting enzyme 2: Implications for a potential treatment for COVID-19. Rev Med Virol. 2020;30(5). e2119. doi: 10.1002/rmv.2119. [PubMed: 32584474]. [PubMed Central: PMC7362103].

6. Hoffmann M, Kleine-Weber H, Schroeder S, Kruger N, Herrler T, Erichsen S, et al.SARS-CoV-2 cell entry depends on ACE2 and TMPRSS2 and is blocked by a clinically proven protease inhibitor. Cell.2020;181(2):271280 e8. doi: 10.1016/j.cell.2020.02.052. [PubMed: 32142651]. [PubMed Central: PMC7102627].

7. Xu H, Zhong L, Deng J, Peng J, Dan H, Zeng X, et al. High expression of ACE2 receptor of 2019-nCoV on the epithelial cells of oral mucosa. Int J Oral Sci. 2020;12(1):8. doi: 10.1038/s41368-020-0074-x. [PubMed: 32094336]. [PubMed Central: PMC7039956].

8. Xu X, Chen P, Wang J, Feng J, Zhou H, Li X, et al. Evolution of the novel coronavirus from the ongoing Wuhan outbreak and modeling of its spike protein for risk of human transmission. Sci China Life Sci. 2020;63(3):457-60. doi: 10.1007/s11427-020-1637-5. [PubMed 32009228]. [PubMed Central: PMC7089049].

9. South AM, Diz DI, Chappell MC. COVID-19, ACE2, and the cardiovascular consequences. Am J Physiol Heart Circ Physiol. 2020;318(5):H108490. doi: 10.1152/ajpheart.00217.2020. [PubMed: 32228252]. [PubMed Central: PMC7191628].

10. Marshall RP, McAnulty RJ, Laurent GJ. Angiotensin II is mitogenic for human lung fibroblasts via activation of the type 1 receptor. Am J Respir Crit Care Med. 2000;161(6):1999-2004. doi: 10.1164/ajrccm.161.6.9907004. [PubMed:10852780].

11. Imai Y, Kuba K, Rao S, Huan Y, Guo F, Guan B, et al. Angiotensinconverting enzyme 2 protects from severe acute lung failure. Nature. 2005;436(7047):112-6. doi: 10.1038/nature03712. [PubMed: 16001071] [PubMed Central: PMC7094998].

12. Sodhi CP, Wohlford-Lenane C, Yamaguchi Y, Prindle T, Fulton WB, Wang $S$, et al. Attenuation of pulmonary ACE2 activity impairs inactivation of des-Arg(9) bradykinin/BKB1R axis and facilitates LPS-induced neutrophil infiltration. Am J Physiol Lung Cell Mol Physiol. 2018;314(1):L17-31. doi: 10.1152/ajplung.00498.2016. [PubMed: 28935640]. [PubMed Central: PMC5866432].

13. Li Y, Zeng Z, Cao Y, Liu Y, Ping F, Liang M, et al. Angiotensin-converting enzyme 2 prevents lipopolysaccharide-induced rat acute lung injury via suppressing the ERK1/2 and NF-kappaB signaling pathways. Sci Rep.2016;6:27911. doi:10.1038/srep27911. [PubMed: 27302421]. [PubMed Central: PMC4908402].

14. Liu T, Zhang L, Joo D, Sun SC. NF-kappaB signaling in inflammation. Signal Transduct Target Ther. 2017;2(1):1-9. doi: 10.1038/sigtrans.2017.23. [PubMed: 29158945]. [PubMed Central: PMC5661633].

15. Holick MF. Vitamin D deficiency. N Engl J Med. 2007;357(3):266-81. doi: 10.1056/NEJMra070553. [PubMed: 17634462].

16. Grant WB, Lahore H, McDonnell SL, Baggerly CA, French CB, Aliano JL, et al. Evidence that vitamin D supplementation could reduce risk of influenza and COVID-19 infections and deaths. Nutrients. 2020;12(4). doi: 10.3390/nu12040988. [PubMed: 32252338]. [PubMed Central: PMC7231123]

17. Cantorna MT, Snyder L, Lin YD, Yang L. Vitamin D and 1,25(OH)2D regulation of T cells. Nutrients. 2015;7(4):3011-21. doi: 10.3390/nu7043011. [PubMed: 25912039]. [PubMed Central: PMC4425186].

18. Shi YY, Liu TJ, Fu JH, Xu W, Wu LL, Hou AN, et al. Vitamin D/VDR signaling attenuates lipopolysaccharideinduced acute lung injury by maintaining the integrity of the pulmonary epithelial barrier. Mol Med Rep 2016;13(2):1186-94. doi: 10.3892/mmr.2015.4685. [PubMed: 26675943] [PubMed Central: PMC4732862].

19. Xu J, Yang J, Chen J, Luo Q, Zhang Q, Zhang H. Vitamin D alleviates lipopolysaccharideinduced acute lung injury via regulation of the reninangiotensin system. Mol Med Rep. 2017;16(5):7432-8. doi: 10.3892/mmr.2017.7546. [PubMed: 28944831]. [PubMed Central: PMC5865875].

20. Yang J, Zhang H, Xu J. [Effect of Vitamin D on ACE2 and Vitamin D receptor expression in rats with LPS-induced acute lung injury]. Chinese J Emerg Med. 2016;25(12):1284-9. Chinian. doi: 10.3760/cma.j.issn.16710282.2016.12.016 


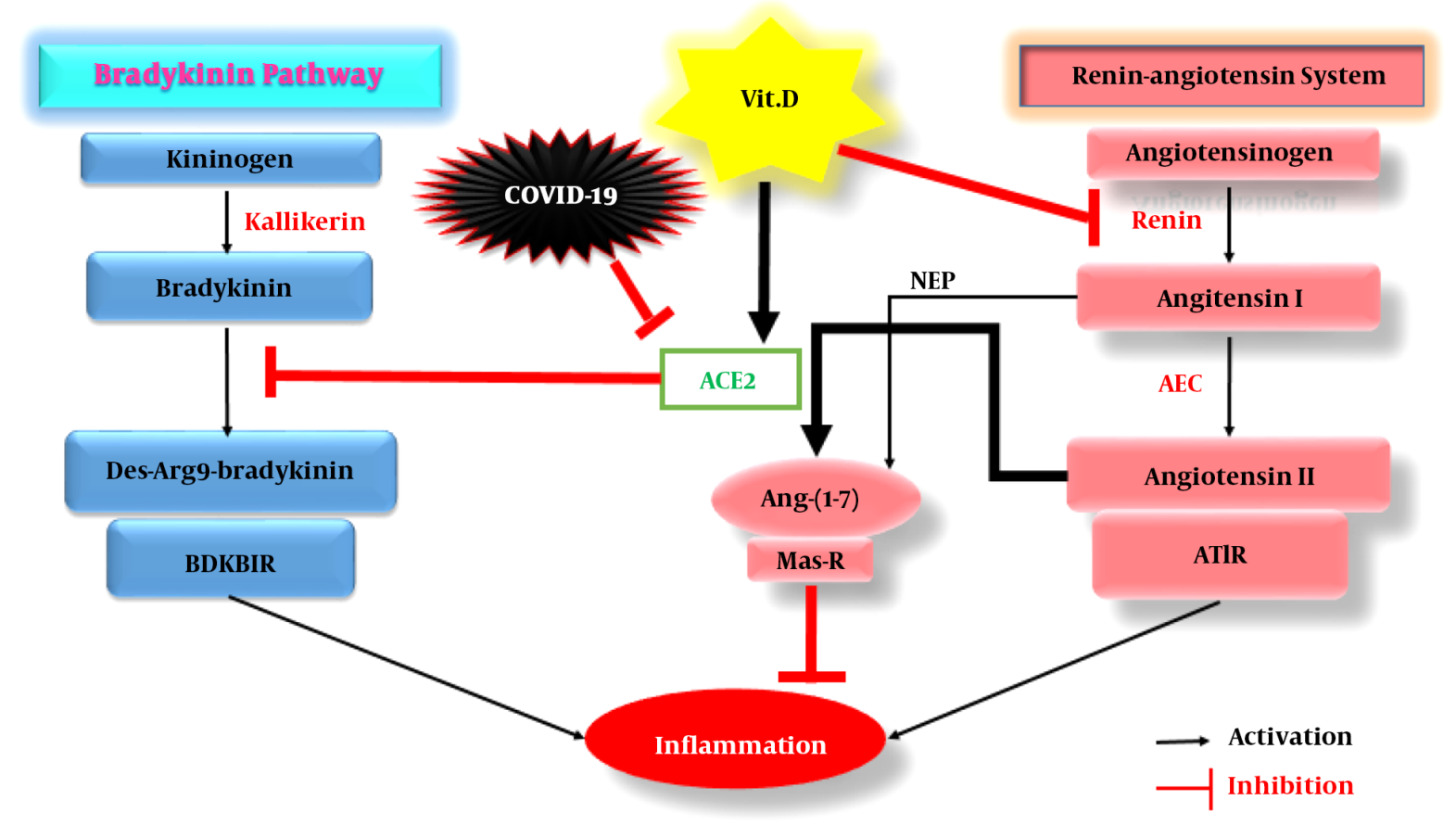

Figure 1. The acting mechanisms of vitamin D on both RAS and bradykinin pathways in COVID-19 patients. Abbreviations: RAS, Renin-angiotensin system; BDKB1R, Bradykinin B1 receptor; Vit. D, Vitamin D; Ang-(1-7), Angiotensin-(1-7); Mas-R, Mas-receptor; ACE2, Angiotensin-converting enzyme 2; ACE, Angiotensin-converting enzyme; AT1R, Angiotensin II receptor type 1; NEP, Endopeptidase. 